\title{
ROLE OF TLC NLR \& SERUM CREATININE IN DIAGNOSING ACUTE APPENDICITIS: A PROSPECTIVE STUDY IN A TERTIARY CARE CENTRE
}

\section{General Surgery}

\author{
Dr. Madhu B S
}

Professor, Department of General Surgery, Mysore Medical College \& Research Institute, Mysore, Karnataka.

\begin{tabular}{ll}
\hline $\begin{array}{l}\text { Dr. Shraddha } \\
\text { Shenoy* }\end{array}$ & Post Graduate Student, Department of General Surgery, Mysore Medical College \& \\
\hline
\end{tabular}

\section{ABSTRACT}

Aim- To assess the role of TLC and NLR and serum creatinine in diagnosing acute appendicitis.

Background-Acute appendicitis being the most common surgical emergency globally can lead to varied consequences if not detected and treated accurately. Early and precise biochemical detectors affect the severity of acute appendicitis.

Materials and methodology-A prospective study was conducted in K R Hospital, Mysore from 2019-2020. All cases of acute appendicitis during this period were assessed for severity. TLC, NLR and serum creatinine were assessed and correlated with severity of acute appendicitis.

Results- A total of 96 patients were included in the study, 72 patients had SAA and 24 had CAA. This was classified in accordance to the cut off values. TC cut off point was 15,050 cells/cumm, Sn $91.7 \%$, Sp 74.6\%. The NLR cutoff value was 4.56, Sn of $83.3 \%$, Sp of $66.2 \%$. The cutoff value for neutrophil count was $77.6 \%$, Sn $91.7 \%$, Sp 71.18\%. The cutoff value for lymphocyte count was $18.2 \%$, Sn was $91.7 \%$, Sp $65.8 \%$. The cutoff value of creatinine was 0.73 , Sn of $83.3 \%$, Sp $80.03 \%$

Conclusion- TC, TLC, NLR and Serum creatinine combinedly help distinguishing between the simple acute appendicitis and complicated acute appendicitis and is a very economical measure for the prediction

\section{KEYWORDS}

complicated acute appendicitis, simple acute appendicitis, total leukocyte count, NLR.

\section{INTRODUCTION}

Acute appendicitis (AA) is common surgical problem associated with acute-phase reaction and also the most common reason for emergency surgeries. It is common between the ages of $7-15$ years but can occur at any age. It is the most common non gestational cause of acute abdomen in pregnancy. ${ }^{[1]}$ Clinically the McBurney's triad consisting of RIF tenderness, fever and vomiting is pathognomonic of the condition but despite the presence of various imaging modalities, biochemical markers, and scoring systems the negative appendectomy rate remain high. $^{[2]}$

In patients with right lower quadrant pain, the total white cell count is an unreliable predictor of appendicitis. However high WBC counts and left shift are independently, strongly associated with appendicitis in children aged 1 to 19 years ${ }^{[3]}$

It has been reported that the lymphocyte count can fall in acute appendicitis necessitating a search for more sensitive criteria. NLR is an emergent novel indicator of severity in these cases. ${ }^{[4]}$ Other lab markers such as $\mathrm{CP}$ (calprotectin), $\mathrm{SAA}-1$ (serum amyloid-A1), CRP were significantly elevated in patients with $\mathrm{AA}^{[5]}$

Role of blood tests alone in decision-making process is unclear. ${ }^{[6]}$ Although all clinical and laboratory variables are weak discriminators individually, they achieve a high discriminatory power when combined. Laboratory examination of the inflammatory response, clinical descriptors of peritoneal irritation, and a history of migration of pain yield the most important diagnostic information and should be included in diagnostic assessment. ${ }^{[7]}$

Our aim was to study the usefulness of universally available investigations total leukocyte count (TLC), percentage neutrophil count, percentage lymphocyte counts, NLR as obtained from differential leukocyte count (DLC) and serum creatinine levels in the diagnosis of acute appendicitis. We also tried to determine the role of NLR in positively diagnosing types of appendicitis (simple and complicated)

\section{MATERIALS \& METHODOGY}

This was a prospective study conducted in K.R.Hospital, Mysore Medical College \& Research Institute, a tertiary care centre from November 2019 to July 2020. The clinical diagnosis of appendicitis was established preoperatively by means of clinical history (abdominal pain, vomiting, and fever), physical examination (tenderness at McBurney's point), traditional laboratory tests (hemoglobin, TLC, and DLC) and in all patients, by imaging studies such as ultrasonography.
Biochemistry tests were performed on blood samples obtained on the day of admission to the hospital. Data collected from the medical records of these patients included the age, gender, the time taken from the onset of the first symptom to the day of presentation (duration of symptoms), clinical symptoms and signs, the TLC, DLC, operative findings, and the histopathology reports.

The Neutrophil-to-Lymphocyte ratio is derived from the counts of circulating neutrophils and lymphocytes, both of which are major leukocyte subpopulations Pathology reports were used to confirm the presence of an inflamed appendix.

According to the intraoperative findings, the patients were grouped into two categories, simple acute appendicitis (SAA), and complicated acute appendicitis (CAA) which was defined as the presence of intraabdominal abscess, perforated appendix, gangrenous appendix, and appendicular mass.

\section{STATISTICALANALYSIS}

The data analysis was performed using the Statistical Package for the Social Sciences for Windows, version 26. The cutoff values of parameters for discrimination of the groups were determined using the receiver operator characteristic (ROC) analysis. At each value, the sensitivity and specificity for each outcome under study were plotted, thus generating an ROC curve. Area under the ROC curve was used to determine the predictive (diagnostic) ability of TLC, NLR, and percentage neutrophil and lymphocyte counts for predicting simple and complicated cases of acute appendicitis. An optimum cutoff value was selected which gave high sensitivity as well as specificity for CAA.

\section{RESULTS}

A total of 96 patients satisfying inclusion and exclusion criteria were included in the study of which 72 patients $(75.0 \%)$ presented with simple acute appendicitis, 24 patients $(25.0 \%)$ with complicated acute appendicitis. Age of the patients ranged from 6 to 55 years with a mean age of $24.8 \pm 13.494$ years.

Of the 96 patients studied, there were 72 patients in group SAA and 24 patients in group CAA. There was a significant difference in the WBC, neutrophil percentage, NLR and serum creatinine results between the complicated group and the uncomplicated group.

The mean WBC count in the complicated group was $(17092.50 \pm$ $1943.65)$ cells $/ \mathrm{mm} 3$, and it was significantly higher than that of the uncomplicated $\mathrm{AA}(12533.33 \pm 3283.28)$ group $(\mathrm{p}<0.002)$

The mean neutrophil count in the complicated group was (83.59 \pm 
6.42) cells/cumm, and it was significantly higher than that of the uncomplicated AA $(72.54 \pm 12.81)$ group $(\mathrm{p}<0.001)$. (Table 1$)$

\begin{tabular}{|c|c|c|c|c|}
\hline \multicolumn{5}{|c|}{$\begin{array}{l}\text { Table 1. Mean values and SD of various biochemical } \\
\text { investigations for Complicated Acute Appendicitis }\end{array}$} \\
\hline FACTOR & $\begin{array}{c}\text { Total } \\
\text { Population } \\
\mathrm{n}=96\end{array}$ & $\begin{array}{c}\text { Simple Acute } \\
\text { Appendicitis } \\
\mathrm{n}=72\end{array}$ & $\begin{array}{c}\text { Complicated } \\
\text { Acute } \\
\text { Appendicitis } \\
\mathrm{n}=24\end{array}$ & $\begin{array}{c}p \\
\text { value }\end{array}$ \\
\hline $\begin{array}{l}\text { Total Count } \\
\left(\text { cells } / \mathrm{mm}^{3}\right) \text {, } \\
\text { mean } \pm \mathrm{SD}\end{array}$ & $\begin{array}{c}13673.12 \pm \\
3592.99\end{array}$ & $\begin{array}{l}12533.33 \pm \\
3283.28\end{array}$ & $\begin{array}{c}17092.50 \pm \\
1943.65\end{array}$ & 0.002 \\
\hline $\begin{array}{c}\text { Neutrophil Count } \\
\left(\text { cells } / \mathrm{mm}^{3}\right), \text { mean } \\
\pm \mathrm{SD}\end{array}$ & $75.31 \pm 12.47$ & $72.54 \pm 12.81$ & $83.59 \pm 6.42$ & 0.001 \\
\hline $\begin{array}{c}\text { Lymphocyte Count } \\
\left(\text { cells } / \mathrm{mm}^{3}\right), \\
\text { mean } \pm \mathrm{SD}\end{array}$ & $19.18 \pm 10.95$ & $21.40 \pm 11.32$ & $12.61 \pm 6.31$ & 0.004 \\
\hline $\begin{array}{c}\text { NLR } \\
\text { mean } \pm \text { SD }\end{array}$ & $6.27 \pm 1.78$ & $5.42 \pm 2.69$ & $8.77 \pm 1.76$ & 0.013 \\
\hline $\begin{array}{c}\text { Serum Creatinine } \\
(\mathrm{mg} / \mathrm{dL}) \\
\text { mean } \pm \mathrm{SD}\end{array}$ & $0.80 \pm 0.18$ & $0.85 \pm 0.14$ & $0.62 \pm 0.12$ & 0.001 \\
\hline
\end{tabular}

The mean lymphocyte count in the complicated group was (12.61 \pm $6.31) \mathrm{cell} / \mathrm{mm} 3$, and it was significantly lower than that of the uncomplicated $\mathrm{AA}(21.40 \pm 11.32)$ group $(\mathrm{p}<0.004)$. (Table 1$)$

The mean NLR in the complicated group was $(8.77 \pm 1.76)$, and it was significantly higher than that of the uncomplicated AA(5.42 \pm 2.69$)$ group $(\mathrm{p}<0.013)$. (Table 1$)$

The mean serum creatinine levels in the complicated group was $(0.62 \pm$ $0.12) \mathrm{mg} / \mathrm{dl}$, and it was significantly lower than that of the uncomplicated $\mathrm{AA}(0.85 \pm 0.14) \mathrm{mg} / \mathrm{dl}$ group $(\mathrm{p}<0.001)$. (Table 1$)$.

The TLC, NLR, and percentage lymphocyte counts were compared in Table 1 . The TLC cutoff value was $15,050 \mathrm{cells} / \mathrm{cu} \mathrm{mm}$. Values greater than this cutoff value were considered to be complicated and values lower than the cutoff value were considered to be simple appendicitis. The sensitivity was $91.7 \%$, specificity was $74.6 \%$, positive likelihood ratio (LR) was 3.61, and negative LR was 0.11 with AUC 0.86 (Table 2)

The NLR cutoff value was 4.56 ; values greater than this were considered to be complicated and values lesser than this were considered to be simple. This resulted in sensitivity of $83.3 \%$, specificity of $66.2 \%, \mathrm{LR}+$ of 2.46 , and LR- of 0.25 with AUC 0.77[Table 2].

The cutoff value for neutrophil count was $77.6 \%$. Values greater than this cutoff value were considered to be complicated and values lesser than this were considered to be simple. The sensitivity was $91.7 \%$ and specificity was $71.18 \%$, LR+3.18, LR- 0.116 , AUC- 0.803 [Table 2]

The cutoff value for lymphocyte count was $18.2 \%$. Values greater than this cutoff value were considered to be simple and values lesser than this were considered to be complicated. The sensitivity was $91.7 \%$,specificity was $65.8 \%$, LR+ was 2.68 , and LR- was 0.121 , AUC 0.857 [Table 2]

The cutoff value for serum creatinine was 0.7350 . Values greater than this cutoff value were considered to be simple and values lesser than this were considered to be complicated. The sensitivity was $83.3 \%$, specificity was $80.03 \%$, LR+ was 4.171 , and LR- was 0.2087 , AUC 0.857 [Table 2]

\begin{tabular}{|c|c|c|c|c|c|c|c|}
\hline \multicolumn{7}{|c|}{ Table 2. Diagnostic values of various Biochemical investigations in } \\
relation to Complicated Acute Appendicitis \\
\hline Factor & AUC & $\begin{array}{c}\text { Cut off } \\
\text { Value }\end{array}$ & Sensitivity & Specificity & LR + & LR - & $\begin{array}{c}p \\
\text { value }\end{array}$ \\
\hline Total Count & 0.866 & 15,050 & $91.7 \%$ & $74.6 \%$ & 3.61 & 0.11 & 0.002 \\
\hline $\begin{array}{c}\text { Neutrophil } \\
\text { Count }\end{array}$ & 0.803 & 77.60 & $91.7 \%$ & $71.18 \%$ & 3.18 & 0.116 & 0.001 \\
\hline $\begin{array}{c}\text { Lymphocyte } \\
\text { Count }\end{array}$ & 0.857 & $\begin{array}{c}18.200 \\
0\end{array}$ & $91.7 \%$ & $65.8 \%$ & 2.68 & 0.121 & 0.004 \\
\hline NLR & 0.773 & 4.5683 & $83.3 \%$ & $66.2 \%$ & 2.46 & 0.252 & 0.01 \\
\hline $\begin{array}{c}\text { Serum } \\
\text { Creatinine }\end{array}$ & 0.857 & 0.7350 & $83.3 \%$ & $80.03 \%$ & 4.171 & 0.2087 & 0.001 \\
\hline
\end{tabular}
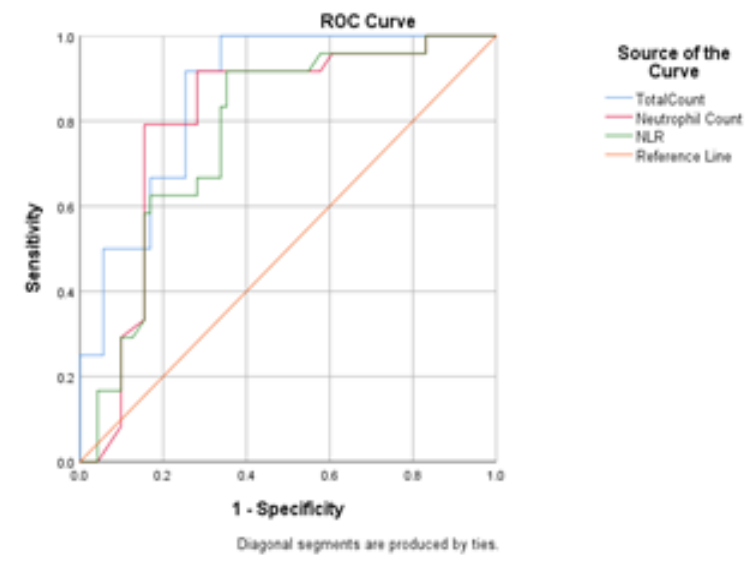

Figure1. Area Under the Curve for TC, NC, NLR
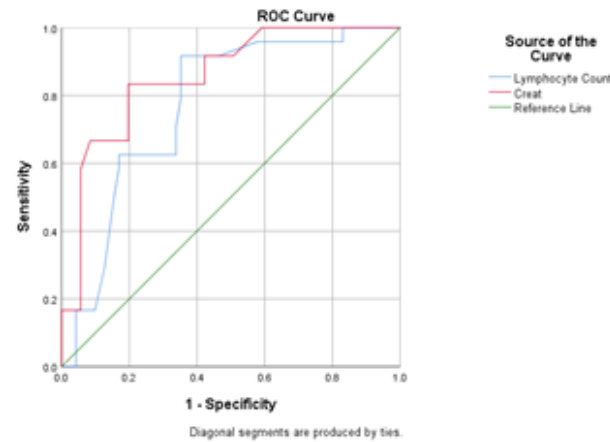

Figure 2. Area Under the Curve for LC, S. Creatinine

\section{DISCUSSION}

The inflammation-triggered release of arachidonic acid metabolites and platelet-activating factors results in neutrophilia, and cortisolinduced stress results in relative lymphopenia ${ }^{[8]}$, which inturn leads to an increase in the NLR and PLR, a sign of inflammation in Acute appendicitis ${ }^{[9,10,11]}$. Increase in the difference between neutrophil and lymphocyte counts reflects severity of inflammatory response. Hence, neutrophil-to lymphocyte ratio has long been used as a marker for many pathologies, including malignancies, chronic inflammatory diseases, and postoperative complications ${ }^{[10,12]}$

This study shows that NLR with a cutoff value of 4.57 can significantly help in differentiating a simple case of acute appendicitis from a complicated one. Most studies done in the past have successfully proved that the NLR ratio has better accuracy than white blood cell counts and CRPs.

This ratio is similar to the ratio derived in previous reports such as in the reports by Kahramanca et al, a NLR cutoff of 5.74 was associated with complicated appendicitis $(\mathrm{p}<0.001)$. The sensitivity and specificity of the value were $70.8 \%$ and $48.5 \%$, respectively. ${ }^{[13]}$ Goodman et al. had put forth the argument that NLR is a more sensitive parameter than the number of leukocytes nearly two and a half decades earlier. ${ }^{[4,14-18]}$

Shimizu et al. ${ }^{[19]}$ suggest a NLR cut-off value of 5.0 for the diagnosis of acute appendicitis, with $44 \%$ sensitivity and $22 \%$ specificity. A study conducted by Yazici et al. ${ }^{[20]}$ showed that a NLR over 3.5 in a pediatric patient group had maximum sensitivity and more sensitivity than the WBC count.

Another study by Ishizuka et al..$^{[9]}$ revealed that an NLR $>8$ had a significant association with gangrenous appendicitis in patients undergoing appendectomy and found a sensitivity and specificity of $73 \%$ and $39 \%$ for the same.

Markar et al. ${ }^{[21]}$ assessed 1117 pediatric patients who underwent appendectomy and determined that the NLR appeared to be of greater diagnostic accuracy than the total WBC count.

In a study population of 3392 subjects cut-off values were $11900 / \mathrm{mm} 3$ 
for WCC (sensitivity: $71.2 \%$; specificity: $67.2 \%$ ) and 3.0 for NLR (sensitivity: $81.2 \%$; specificity: $53.1 \%$ ). Serum bilirubin and NLR were independent variables for the diagnosis of perforated appendicitis. ${ }^{[22]}$

Our study shows that at a TLC cutoff value of 15,050 cells $/ \mathrm{mm}$ to differentiate simple appendicitis from complicated appendicitis , the specificity and sensitivity is slightly higher, when compared to the NLR ratio.

Thus, TLC and NLR seem to be equally dependable indicators of simple or complicated appendicitis. Other similar studies, Al-Gaithy et al. reported a cutoff limit of TLC 11,100 cells $/ \mathrm{mm}$ and Hotic et al. reported a neutrophil cutoff count of 15,760 cells $/ \mathrm{mm}$ to differentiate complicated appendicitis from simple appendicitis.

Studies have shown that WBC counts are always elevated in complicated appendicitis such as phlegmon and perforation. ${ }^{[7,6]}$ Appendicitis patients had significantly lower blood creatinine level as compared to other intraabdominal emergent conditions. ${ }^{[23]}$

These above studied parameters and cutoff to differentiate the two entities clinically is extremely useful considering the management of the sequel of complicated appendicitis. Where Non-operative management with antibiotics alone may be an option for patients with uncomplicated appendicitis; however, surgery is the first choice for complicated AA, and especially gangrenous appendicitis as severe phlegmonous or gangrenous appendiceal inflammation can easily lead to peritonitis if perforation occurs. ${ }^{[24-27,7]}$

The NLR and TLC, serum creatinine levels being simple, noninvasive, and cost-effective inflammatory markers can easily be calculated from the blood profile in the emergency department. However, the role of the latter in AA has only been investigated in a few studies. There are limitations to this study, for example, the data were only collected for a 1-year period, which may not show the real potential of NLR, TLC and serum creatinine levels in the discrimination of complicated AA.

In conclusion, our study revealed that high NLR and low serum creatinine levels might help identify those who are more likely to develop complications in patients with AA. Moreover, these parameters are not expensive to measure, are easily available, and the short time required for analysis is valuable in the emergency department.

Hence these values combined with the results of a physical examination, imaging studies, and other laboratory tests to help identify high-risk AA patients in the emergency department

\section{Conflict of interest: None declared \\ CONCLUSION}

NLR, TLC and serum creatinine levels are reliable parameters that can be considered in distinguishing complicated appendicitis from SAA. However, the blood tests in themselves are inconclusive if not correlated with the clinical findings and radiology but may help as an added indicator for the surgeon to expect complications and determine better outcome for the patient.

\section{REFERENCES}

1. Yazar FM, Bakacak M, Emre A, Urfalıglu A, Serin S, Cengiz E, et al. Predictive role of neutrophil-to-lymphocyte and platelet-to-lymphocyte ratios for diagnosis of acute appendicitis during pregnancy. Kaohsiung J Med Sci 2015;31:591-6

2. Kuotho T Nyuwi, Ch Gyan Singh, Sridartha Khumukcham, Raju Rangaswamy, Yibenthung S Ezung, Sowdin Reddy Chittvolu, A Barindra Sharma, H Manihar Singh The role of serum fibrinogen level in the diagnosis of acute appendicitis J Clin Diagn Res The role of serum fibrinogen level in the diagnosis of acute appendicitis J Clin Diagn Res

3. Linda T Wang ${ }^{1}$, Kimball A Prentiss, Jill Z Simon, Daniel P Doody, Daniel P Ryan The use of white blood cell count and left shift in the diagnosis of appendicitis in children Pediatr Emerg Care 2007 Feb;23(2):69-76. doi: 10.1097/PEC.0b013e31802d1716.

4. Goodman DA, Goodman CB, Monk JS. Use of the neutrophil: Lymphocyte ratio in the diagnosis of appendicitis. Am Surg. 1995;61:257-9. [PubMed: 7887542]

5. Dirk H S M Schellekens ${ }^{1}$, Karel W E Hulsewé, Bernadette A C van Acker, et al. Evaluation of diagnostic accuracy of plasma markers for early diagnosis in patients suspected for acute appendicitis Acad Emerg Med 2013 Jul;20(7):703-10. doi: suspected for acute

6. Al-Gaithy ZK. Clinical value of total white blood cells and neutrophil counts in patients with suspected appendicitis: Retrospective study. World J Emerg Surg. 2012;7:32. [PMCID: PMC3502286]

7. Andersson RE. Meta-analysis of the clinical and laboratory diagnosis of appendicitis. $\mathrm{Br}$ J Surg 2004;91:28-37

8. Smith TL, Weyrich AS. Platelets as central mediators of systemic inflammatory responses. Thromb Res 2011;127:391-4

9. Ishizuka M, Shimizu T, Kubota K. Neutrophil-to-lymphocyte ratio has a close association with gangrenous appendicitis in patients undergoing appendectomy. In Surg 2012;97:299-304.

10. Zahorec R. Ratio of neutrophil to lymphocyte counts-rapid and simple parameter of systemic inflammation and stress in critically ill. BratislLekListy. 2001; 102:5-14.

11. Zani A, Teague WJ, Clarke SA, Haddad MJ, Khurana S, Tsang T, et al. Can common serum biomarkers predict complicated appendicitis in children? Pediatr Surg In 2017;33:799-805

12. Grivennikov SI, Greten FR, Karin M. Immunity, inflammation, and cancer. Cell. 2010 140:883-99

13. Kahramanca S, Ozgehan G, Seker D, Gökce EI, Seker G, Tunc G, et al. Neutrophil-tolymphocyte ratio as a predictor of acute appendicitis. Ulus TravmaAcilCerrahiDerg. 2014; 20:19-22

14. Mihajlovic D, Lendak D, Mitic G, Cebovic T, Draskovic B, Novakov A et al. Prognostic value of hemostasis-related parameters for prediction of organ dysfunction and mortality in sepsis. Turk J Med Sci. 2015; 45:93-8.

15. Kim CH, Kim SJ, Lee MJ, Kwon YE, Kim YL, Park KS et al. An increase in mean platelet volume from baseline is associated with mortality in patients with severe sepsis or septic shock. PLoS One. 2015; 10:e119437.

16. Kisacik B, Tufan A, Kalyoncu U, Karadag O, Akdogan A, Ozturk MA, et al. Mean platelet volume (MPV) as an inflammatory marker in ankylosing spondylitis and rheumatoid arthritis. Joint Bone Spine. 2008; 75:291-4.

17. Leader A, Pereg D, Lishner M. Are platelet volume indices of clinical use? A multidisciplinary review. Ann Med. 2012;44:805-16.

18. Miller DF, Irvine RW Jaundice in acute appendicitis. Lancet. 1969:94.201-6

19. Shimizu T, Ishizuka M, Kubota K. A lower neutrophil to lymphocyte ratio is closely associated with catarrhal appendicitis versus severe appendicitis. Surg Today. 2016; $46: 84-9$

20. Yazici M, Ozkisacik S, Oztan MO, Gürsoy H. Neutrophil/lymphocyte ratio in the diagnosis of childhood appendicitis. Turk J Pediatr. 2010;52:400-3. [PubMed 21043386]

21. Markar SR, Karthikesalingam A, Falzon A, Kan Y. The diagnostic value of neutrophil: lymphocyte ratio in adults with suspected acute appendicitis. Acta Chir Belg. 2010; 110:543-7

22. Sevinç MM, Kınacı E, Cakar E, Bayrak S, Özakay A, Aren A, et al. Diagnostic value of basic laboratory parameters for simple and perforated acute appendicitis: an analysis of 3392 cases. Ulus Travma Acil Cerrahi Derg 2016;22:155-62.

23. Lakhmir S. Chawla1,6, Ian Toma2, Danielle Davison1, Khashayar Vaziri3, Julie Lee1,3, Raymond Lucas5, Acute appendicitis: transcript profiling of blood identifies promising biomarkers and potential underlying processes

24. Morrow SE, Newman KD. Current management of appendicitis. Semin Pediatr Surg 2007;16:34-40.

25. Marzuillo P, Germani C, Krauss BS, Barbi E. Appendicitis in children ess than five years old: A challenge for the generalpractitioner. World J Clin Pediatr 2015;4:19-24.

26. Singh M, Kadian YS, Rattan KN, Jangra B. Complicated appendicitis: analysis of risk factors in children. Afr J Paediatr Surg 2014;11:109-13.

27. Tehrani HY, Petros JG, Kumar RR, Chu Q. Markers of severe appendicitis. Am Surg $1999 ; 65: 453-5$ 